\title{
Thermal Expansion Coefficient, Temperature Coefficient of Young's Modulus and Equilibrium Diagram of Ferromagnetic Cobalt-Manganese Alloys*
}

\author{
By Hakaru Masumoto**, Shôhachi Sawaya** \\ and Michio Kikuchi**
}

\begin{abstract}
Measurements of the thermal expansion, natural frequency of vibrations and magnetization in ferromagnetic cobaltmanganese alloys were carried out at various temperatures, and an equilibrium diagram was proposed. The equilibrium diagram shows that the $\varepsilon-\alpha$ transformation continues up to a composition range of $19.30 \% \mathrm{Mn}$ and the magnetic transformation point in the $\alpha$ phase is $0^{\circ} \mathrm{C}$ at a composition of $28.20 \% \mathrm{Mn}$. Further, the thermal expansion coefficient and the temperature coefficient of Young's modulus at room temperature were determined, from which it has been ascertained that a $\mathrm{Co}-23.85 \% \mathrm{Mn}$ alloy in the ferromagnetic region of the $\alpha$ phase shows a minimum value of $14.04 \times 10^{-6}$ in thermal expansion coefficient and a maximum value of $2.52 \times 10^{-5}$ in temperature coefficient of Young's modulus. The cause of such anomalous properties of the alloy can be explained by Masumoto's rule in regard to Invar.
\end{abstract}

(Received February 18, 1970)

\section{Introduction}

Masumoto introduced a rule ${ }^{(1)}$ pertaining to a very low temperature coefficient of thermal expansion in Invar, and discovered, through its applications, several Invartype alloys $^{(2)}$ in collaboration with other workers. Extending his rule to account for the Elinvar property, he also invented a number of Elinvar-type alloys ${ }^{(3)}$. According to the rule, the Invar or the Elinvar property is generally exhibited in ferromagnetic solid solutions whose Curie points are found in the vicinity of room temperature. Therefore, research is now concentrated on the alloys which can meet this requirement.

On the other hand, equilibrium diagrams of $\mathrm{Co}-\mathrm{Mn}$ alloys have been studied by Hashimoto ${ }^{(4)}$, Köster and Schmidt ${ }^{(5)}$ and other workers (cf. Fig. 1). It is shown that the $\varepsilon-\alpha$ transformation point of Co discovered by one of the present authors ${ }^{(6)}$ arrives at room temperature at a composition of $31.6 \% \mathrm{Mn}$, and the rest of the alloys whose compositions range from this concentration to about $53 \% \mathrm{Mn}$ is in $\alpha$ solid solutions. With increasing Mn content, the magnetic transformation point descends linearly from the temperature of $1115^{\circ} \mathrm{C}$ for pure $\mathrm{Co}$ and arrives at $0^{\circ} \mathrm{C}$ at $38 \% \mathrm{Mn}$. Accordingly, experiments

* This paper was presented at the 1968 Spring Meeting of the Japan Institute of Metals. Reported originally in Japanese in J. Japan Inst. Metals, 33 (1969), 999. The 35th report from The Foundation : The Research Institute of Electric and Magnetic Alloys, Sendai, Japan.

** The Foundation : The Research Institute of Electric and Magnetic Alloys, Sendai, Japan.

(1) H. Masumoto : Kinzoku-no-kenkyu, 8 (1931), 237 ; Sci. Rep. Tohoku Imp. Univ., 20 (1931), 121.

(2) Stainless-Invar, H. Masumoto : J.Japan Inst. Metals, 4(1940), 141; Sci. Rep. Tohoku Imp. Univ., 23 (1934), 265. Fe-Pt alloys, H. Masumoto : Japan patent No. 207 (Feb. 24, 1936); H. Masumoto and T. Kobayashi : J. Japan Inst. Metals, 126 (1948), 1; Sci. Rep. RITU, A-2 (1950), 856 ; H. Masumoto and T. Kobayashi : J. Japan Inst. Metals, 27 (1963), 459; Trans. JIM, 6 (1965), 113.

(3) Co-Elinvar, H. Masumoto and H. Saitô : J.Japan Inst. Metals, 8 (1944), 513 ; Sci. Rep. RITU, A-1 (1949), 17. Velinvar, H.

Trans. J I M were carried out around the range where the magnetic transformation point reaches room temperature, because it can be expected that the Elinvar property may also be exhibited in this alloy system. However, since these phase diagrams can hardly be said to be well-established,

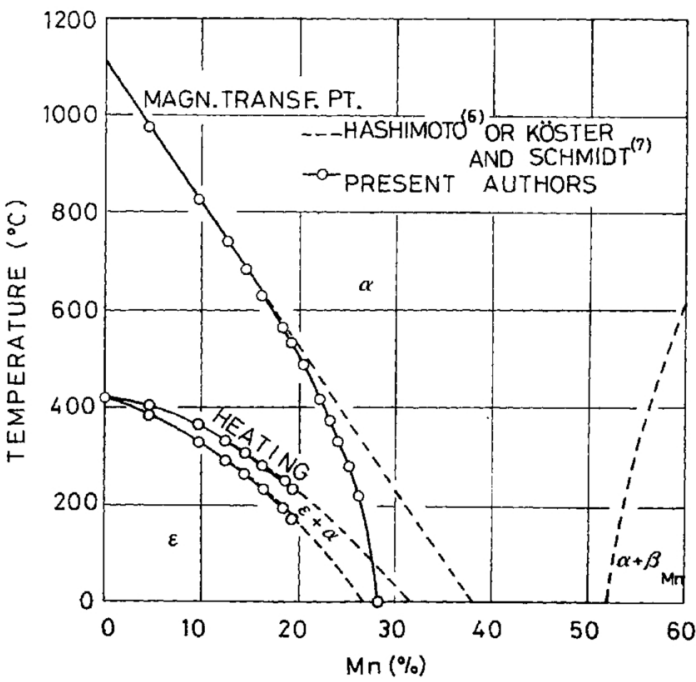

Fig. 1 Equilibrium diagram of Co-Mn alloys.

Masumoto, H. Saitô and T.Kobayashi : J.Japan Inst. Metals, 16 (1952), 420; Sci. Rep. RITU, A-4 (1952), 256. Moelinvar, H. Masumoto, H. Saitô, Y. Sugai and T. Kôno : J. Japan Inst. Metals, 24 (1960), 44, 308; Trans. JIM, 3 (1962), 4. Tungelinvar, H. Masumoto, H. Saitô, Y.Sugai and O.Tezuka : J. Japan Inst. Metals, 25 (1961), 710; Sci. Rep. RITU, A-15 (1963), 206. Mangelinvar, H. Masumoto, H. Saitô and $Y$. Sugai : J. Japan Inst. Metals, 28 (1964), 96. Elcolloy, H. Masumoto, H. Saitô and T. Kobayashi : Japan patent, Showa 31-10507. Fe-Pd alloys, H. Masumoto, H. Saitô and T. Kobayashi : J.Japan Inst. Metals, 27 (1963), 263 ; Trans. JIM, $4(1963), 114$. Co-Pd alloys, H. Masumoto and S. Sawaya : J. Japan Inst. Metals, 33 (1969), 685.

(4) U. Hashimoto : Kinzoku-no-kenkyu, 9 (1932), 64 ; J. Japan Inst. Metals, 1 (1937), 177.

(5) W. Köster und W. Schmidt : Arch. Eisenhütt., 8(1934), 25.

(6) H. Masumoto : Kinzoku-no-kenkyu, 2(1925), 877 ; Sci. Rep. Tohoku Imp. Univ., 15 (1926), 449. 
the diagrams were scrutinized and the Elinvar property was also investigated.

\section{Specimens and Measurements}

The alloying materials used were electrolytic Co and electrolytic Mn, analytical results of which are summarized in Table 1. For the preparation of specimens, tion point on the curves descends gradually and then disappears at a composition of $20.50 \%$ Mn. Similarly, with increasing Mn content, the magnetic transformation point is lowered gradually and disappears completely at $30.20 \% \mathrm{Mn}$. The gradient of the curves in the ferromagnetic region is slower than in the nonmagnetic region, indicating the Invar property.

Figure 3 shows the temperature vs. $\left(f_{t} \mid f_{-150}\right)^{2}$ for

Table 1 Analytical results of cobalt and manganese used

\begin{tabular}{c|c|c|c|c|c|c|c|c}
\hline & $\mathrm{Fe}(\%)$ & $\mathrm{Ni}(\%)$ & $\mathrm{Al}(\%)$ & $\mathrm{Mn}(\%)$ & $\mathrm{Si}(\%)$ & $\mathrm{C}(\%)$ & $\mathrm{P}(\%)$ & $\mathrm{S}(\%)$ \\
\hline Electrolytic Co & 0.120 & 0.010 & 0.033 & 0.001 & 0.012 & 0.028 & 0.002 & 0.006 \\
" $\mathrm{Mn}$ & 0.007 & 0.000 & 0.000 & - & 0.008 & 0.007 & trace & 0.030 \\
\hline
\end{tabular}

Co was first melted in an alumina crucible in hydrogen atmosphere with a high-frequency induction furnace. The molten alloy was cast into an iron mold $10 \mathrm{~mm}$ in inner diameter, wrought to a rod of $2 \mathrm{~mm}$ diameter at room temperature by forging and swaging, and then cut out in a length of $10 \mathrm{~cm}$. 22 alloy specimens were measured. All the specimens were heated in vacuum at $1000^{\circ} \mathrm{C}$ for $1 \mathrm{hr}$, and then cooled at a rate of $300^{\circ} \mathrm{C} / \mathrm{hr}$. However, for X-ray measurements, part of the specimen was ground to 275-mesh powder, vacuum sealed in a silica glass tube, and then heat treated in the same way as mentioned above.

Thermal expansion $\Delta l / l$ measurements were carried out over the temperature range of $-150^{\circ} \sim 1000^{\circ} \mathrm{C}$ by the vertical-type dilatometer ${ }^{(7)}$ and the horizontal-type dilatometer, in order to obtain the mean linear coefficient of thermal expansion at room temperature. The number of natural frequencies $f(800 \sim 1000 \mathrm{~Hz})$ was measured at $-150^{\circ} \sim 500^{\circ} \mathrm{C}$ by the vibration-controlled oscillator system $^{(8)}$. Young's modulus $E$ at $20^{\circ} \mathrm{C}$ and its temperature coefficient $\boldsymbol{e}$ near room temperature were calculated from the measured data on the thermal expansion coefficient $\alpha$ and the density $D$. Magnetic analysis was carried out at $20^{\circ} \sim 950^{\circ} \mathrm{C}$ by the ballistic method. The density was determined by weighing in water, the hardness $\mathrm{Hv}$ by the Vickers hardness tester, and the electrical resistivity $\rho$ by the potentiometric method. The microstructures of the alloys were observed on an optical microscope using the specimens which were corroded in a $0.5 \%$ picric acid-alcohol solution at $15^{\circ} \mathrm{C}$ for 10 15 min. The crystallographic structure of the specimens were determined by the $\mathrm{X}$-ray diffractometer method.

\section{Experimental Results and Discussion}

The experimental results are summarized in Figs. 2 6 and Table 2. Figure 2 shows the thermal expansion curves for Co-Mn alloys containing less than $30.20 \%$ Mn. With increasing Mn content, the $\varepsilon-\alpha$ transforma-

(7) H. Masumoto and T. Kobayashi : J. Japan Inst. Metals, 12-6 (1948), 1; Sci. Rep. RITU, A-2 (1950), 856.

(8) Y. Shirakawa and I. Oguma, J. Japan Inst. Metals, 24 (1960), 63; Sci. Rep. RITU, A-18 Suppl., (1966), p. 523.

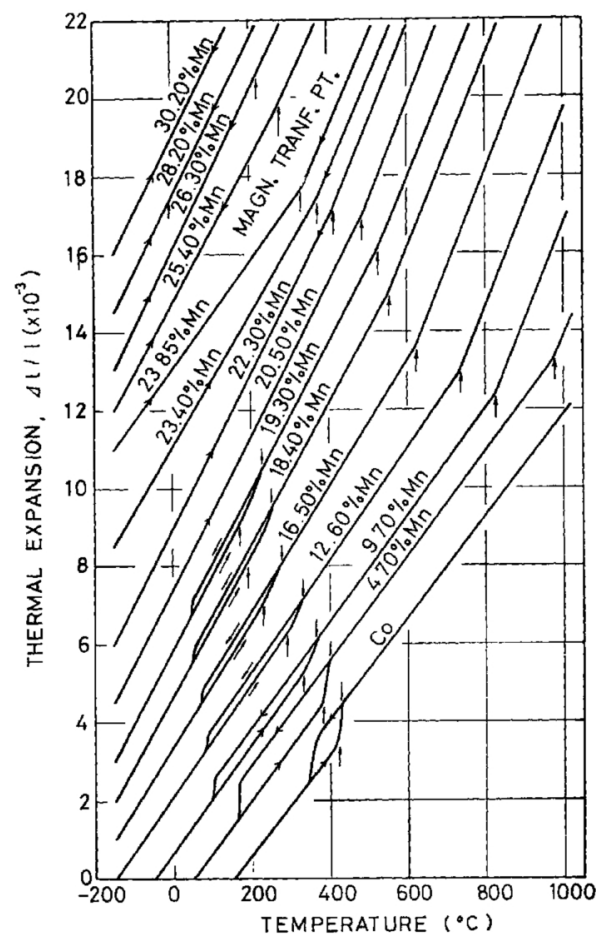

Fig. 2 Thermal expansion of Co-Mn alloys.

Co-Mn alloys containing less than $59.00 \% \mathrm{Mn}$, where $f_{t}$ and $f_{-150}$ are the numbers of natural frequencies at $t^{\circ}$ and $-150^{\circ} \mathrm{C}$, respectively. In the figure, the $\varepsilon-\alpha$ transformation is revealed distinctly, but the variation corresponding with the magnetic transformation point can hardly be observed.

Figure 4, shows the magnetization vs. temperature curves for Co-Mn alloys containing less than $26.30 \%$ $\mathrm{Mn}$, where both the $\varepsilon-\alpha$ transformation and the magnetic transformation point appear distinctly. The composition dependence of the $\varepsilon-\alpha$ transformation and the magnetic transformation point was derived from these figures, and is shown with open circles in Fig 1. As can be seen in the figure, the $\varepsilon-\alpha$ transformation appears at compositions up to $19.30 \% \mathrm{Mn}$ and disappears at $20.50 \% \mathrm{Mn}$. This is a matter of course in view of the fact that Photo. 1 (a) and (b), and (c), (d), (e) and (f) show the structures characteristic of the $\varepsilon$ phase and the $\alpha$ phase, respectively. To confirm the $\varepsilon$ and $\alpha$ phase boundaries, $\mathrm{X}$-ray analysis was carried out. In agreement with the above-mentioned 
observation, the results showed that the $19.30 \% \mathrm{Co}-\mathrm{Mn}$ alloy consisted of a hexagonal $\varepsilon$ phase and the $20.50 \%$ Co-Mn alloy comprised a face-centered cubic $\alpha$ phase only with no hexagonal one. The magnetic transformation point descends linearly up to a composition of about $15 \%$ $\mathrm{Mn}$, beyond which it is lowered increasingly and finally reaches $0^{\circ} \mathrm{C}$ at $28.20 \% \mathrm{Mn}$.

These results are remarkably inconsistent with the phase diagrams of Hashimoto, Köster and Schmidt as shown in Fig. 1. This may be ascribed to the fact that negligibly small amounts of impurities such as $\mathrm{C}$ which

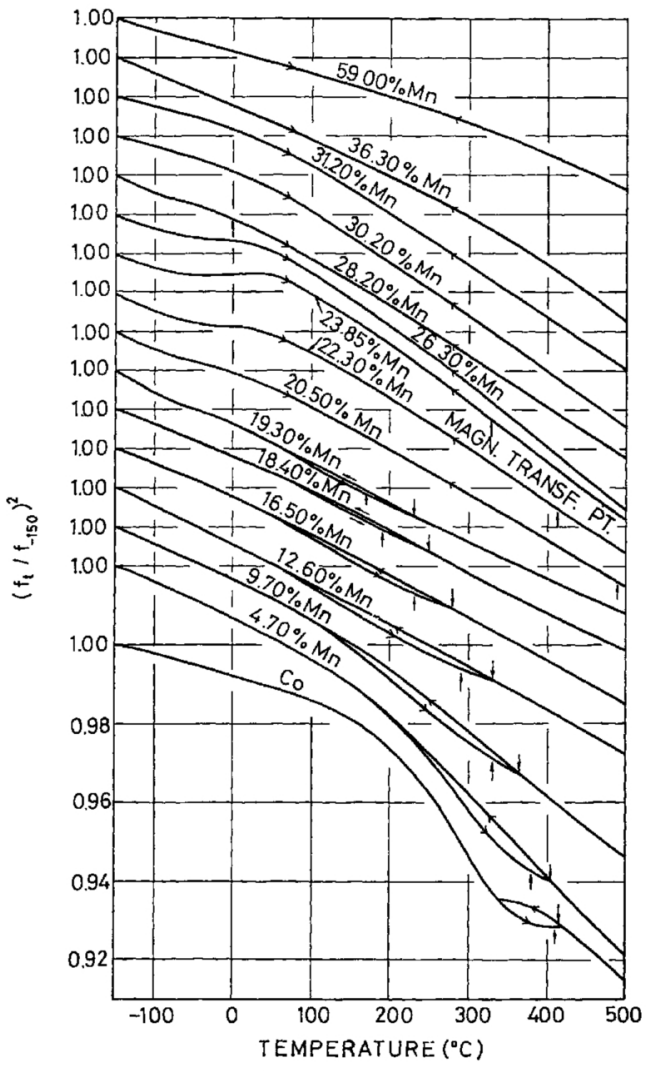

Fig. 3 Temperature dependence of natural frequencies in Co-Mn alloys. would give considerable influence on the nature of alloys are contained in Co and $\mathrm{Mn}$ available today as compared with those some 30 years ago.

Figure 5 shows the composition dependence of Young's modulus and its temperature coefficient, the mean linear coefficient of thermal expansion, density, electrical resistivity and Vickers hardness near room temperature for $\mathrm{Co-Mn}$ alloys. As can be seen in the figure, the density, Young's modulus and hardness indicate unusually low values in the $\varepsilon$ phase range, and the electrical resistivity shows a very high value. This is probably because of the formation of microcracks caused by localized contraction and expansion in the interior structure of the alloys when the alloys undergo the cubic to hexagonal transformation. It is also noted that both the linear

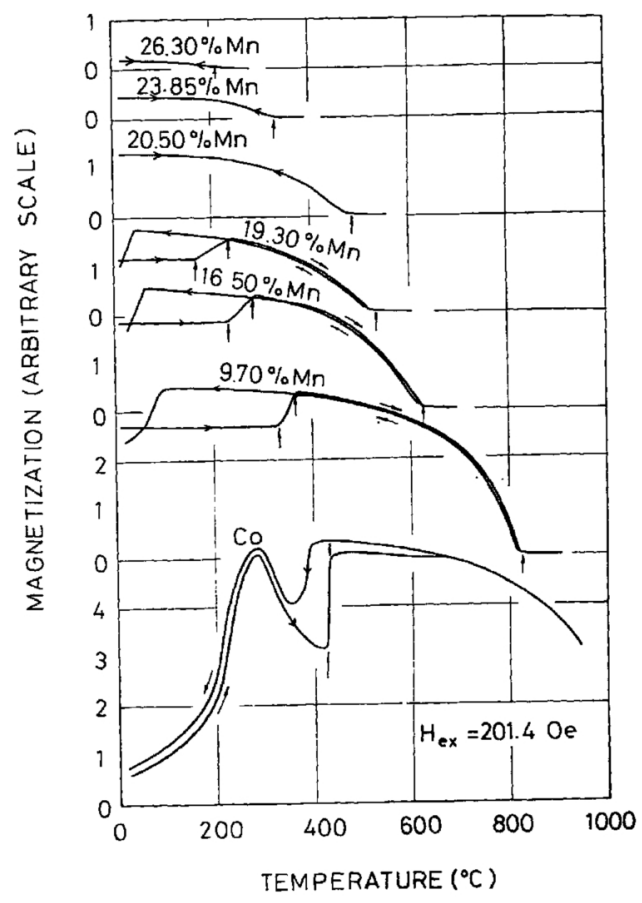

Fig. 4 Temperature dependence of magnetization in Co-Mn alloys.

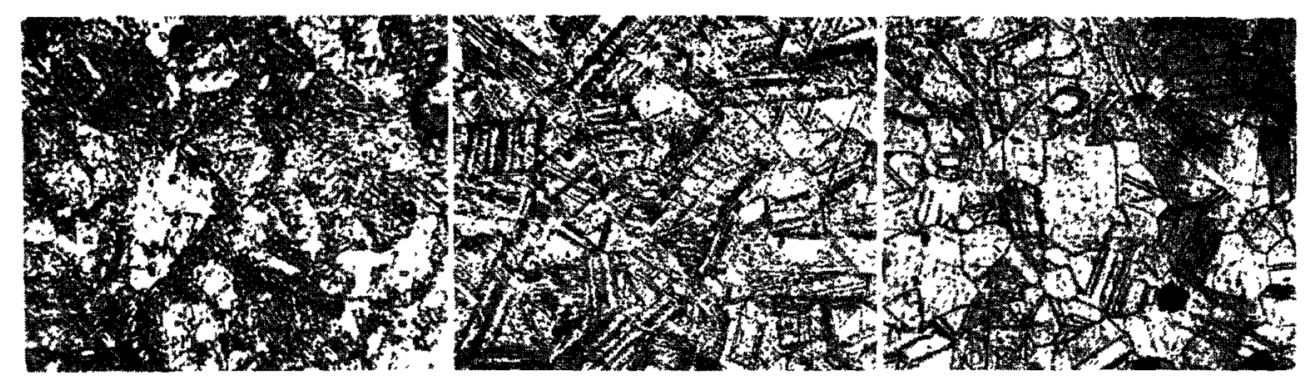

(a) Co

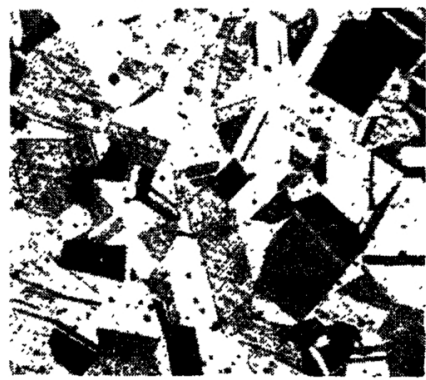

(d) $23.85 \% \mathrm{Mn}$ (b) $19.30 \% \mathrm{Mn}$

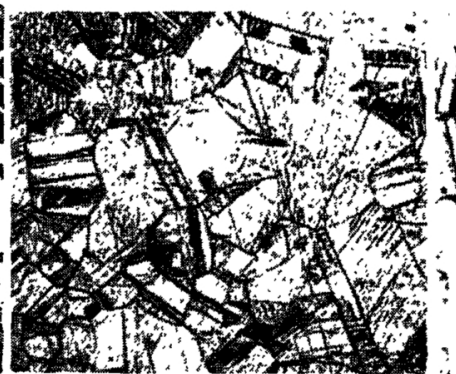

(e) $28.20 \% \mathrm{Mn}$ (c) $20.50 \% \mathrm{Mn}$

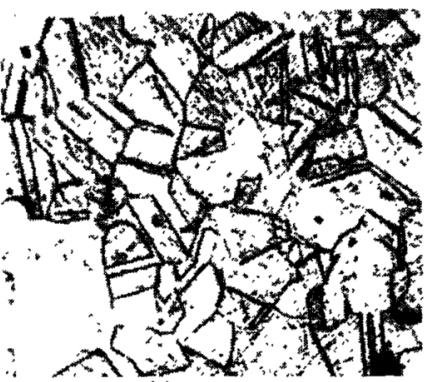

(f) $33.65 \% \mathrm{Mn}$

Photo. 1 Microscopic structures of annealed Co-Mn alloys. $(\times 132)$ 
coefficient of thermal expansion and the temperature coefficient of Young's modulus show a pronounced minimum value of $14.04 \times 10^{-6}$ and a very high maximum value of $2.52 \times 10^{-5}$, respectively, for a composition of $23.85 \% \mathrm{Mn}$ which falls within the $\alpha_{\text {ferromag. }}$ range.

In order to elucidate this anomalous characteristic, the present authors measured the saturation magnetization $I_{s}$, the magnetic transformation point $\theta$ and its ratio $I_{s} \mid \theta$, and drew up curves for the composition dependence of these parameters as shown in Fig. 6. As can be seen in the figure, the value of $I_{s} \mid \theta$ reaches a maximum at $23.85 \%$ $\mathrm{Mn}$, and it is self-evident by analogy with Masumoto's

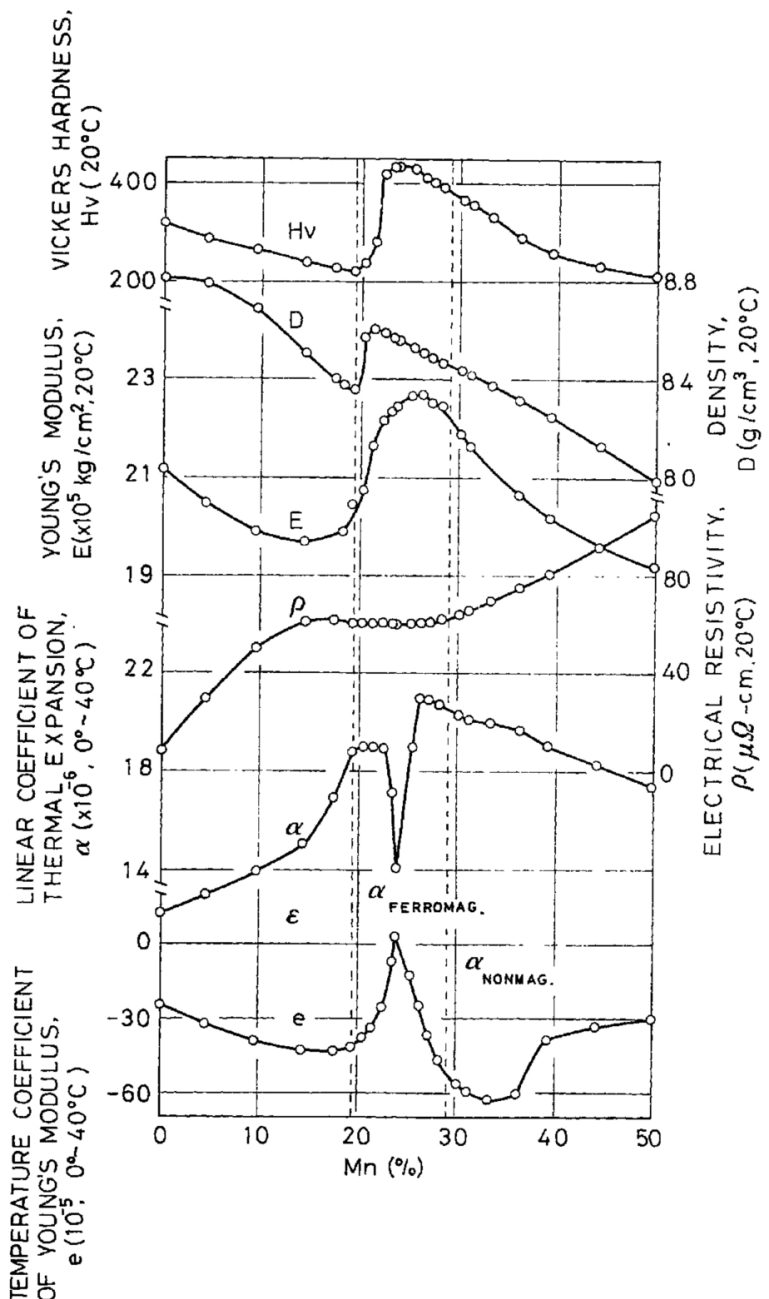

Fig. 5 Composition dependence of Young's modulus and its temperature coefficient, Vickers hardness, density, electrical resistivity and the mean linear coefficient of thermal expansion in Co-Mn alloys. rule ${ }^{(1)}$ that a minimum coefficient of thermal expansion should be revealed at the same composition. The fact that a maximum temperature coefficient of Young's modulus appears at the same composition can also be satisfactorily explained in accordance with the rule.

Table 2 illustrates the results of measurements near room temperature on Co-Mn alloys, especially the alloys with the Elinvar property.

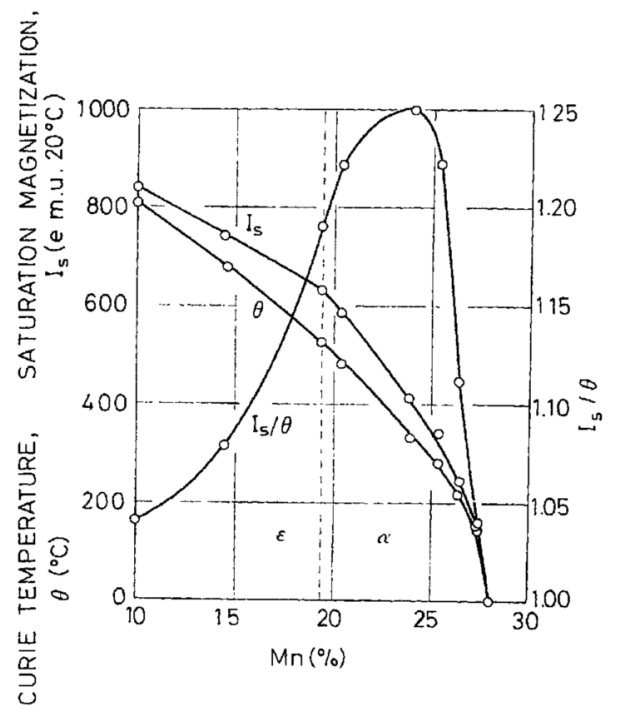

Fig. 6 Relation between curie temperature $\theta$, saturation magnetization $I_{s}$ and $I_{s} / \theta$, and composition in $\mathrm{Co}-\mathrm{Mn}$ alloys.

\section{Conclusions}

Measurements of the thermal expansion at $-150^{\circ} \sim$ $1000^{\circ} \mathrm{C}$, the number of natural frequencies at $-150^{\circ} \sim$ $500^{\circ} \mathrm{C}$, magnetization at $20^{\circ} \sim 950^{\circ} \mathrm{C}$, and the density, electrical resistivity and hardness were conducted on pure Co and $21 \mathrm{Co-Mn}$ alloys, up to $55 \% \mathrm{Mn}$, which were cooled at a rate of $300^{\circ} \mathrm{C} / \mathrm{hr}$ after heating at $1000^{\circ} \mathrm{C}$ for $1 \mathrm{hr}$. The results obtained are as follows :

(1) In the equilibrium diagrams of $\mathrm{Co}-\mathrm{Mn}$ alloys the $\varepsilon-\alpha$ transformation exists up to the composition range of $19.30 \% \mathrm{Mn}$, and the magnetic transformation point of $1115^{\circ} \mathrm{C}$ for pure $\mathrm{Co}$ reaches room temperature at a composition of $28.20 \% \mathrm{Mn}$.

(2) In the range of the $\varepsilon$ phase the density, Young's modulus and hardness at room temperature show exceptionally low values, but the electrical resistivity indicates a high value. This may be ascribed to the formation of

Table 2 Young's modulus $E$ and its temperature coefficient $e$, the mean linear coefficient of thermal expansion $\alpha$, Vickers hardness $\mathrm{Hv}$, density $D$, electrical resistivity $\rho$ and curie temperature $\theta$ of some Co-Mn alloys

\begin{tabular}{|c|c|c|c|c|c|c|c|c|}
\hline $\begin{array}{l}\text { Alloy } \\
\text { No. }\end{array}$ & $\underset{(\%)}{M n}$ & $\begin{array}{c}E\left(\times 10^{5} \mathrm{~kg} /\right. \\
\left.\mathrm{cm}^{2}, 20^{\circ} \mathrm{C}\right)\end{array}$ & $\begin{array}{l}e\left(\times 10^{-5},\right. \\
\left.0^{\circ} \sim 40^{\circ} \mathrm{C}\right)\end{array}$ & $\begin{array}{c}\alpha\left(\times 10^{-6},\right. \\
\left.0^{\circ} \sim 40^{\circ} \dot{\mathrm{C}}\right)\end{array}$ & $\underset{\left(20^{\circ} \mathrm{G}\right)}{\mathrm{Hv}}$ & $\begin{array}{c}D\left(\mathrm{~g} / \mathrm{cm}^{3}\right. \\
\left.20^{\circ} \mathrm{C}\right)\end{array}$ & $\begin{array}{c}\rho(\mu \Omega-\mathrm{cm}, \\
\left.20^{\circ} \mathrm{C}\right)\end{array}$ & $\theta\left({ }^{\circ} \mathrm{C}\right)$ \\
\hline $\begin{array}{r}4 \\
5 \\
6 \\
7 \\
8 \\
9 \\
10 \\
11 \\
12 \\
13\end{array}$ & $\begin{array}{l}14.50 \\
19.30 \\
22.30 \\
23.30 \\
23.70 \\
23.85 \\
24.90 \\
25.40 \\
26.30 \\
27.28\end{array}$ & $\begin{array}{l}19.72 \\
20.45 \\
22.18 \\
22.39 \\
22.42 \\
22.45 \\
22.61 \\
22.68 \\
22.69 \\
22.50\end{array}$ & $\begin{array}{r}-42.50 \\
-42.66 \\
-25.80 \\
-7.03 \\
-4.00 \\
+2.52 \\
-7.02 \\
-13.47 \\
-25.00 \\
-37.00\end{array}$ & $\begin{array}{l}15.02 \\
18.81 \\
18.67 \\
17.13 \\
16.40 \\
14.04 \\
17.20 \\
19.03 \\
20.90 \\
20.90\end{array}$ & $\begin{array}{l}240 \\
220 \\
425 \\
435 \\
434 \\
433 \\
432 \\
429 \\
416 \\
405\end{array}$ & $\begin{array}{l}8.50 \\
8.36 \\
8.60 \\
8.57 \\
8.56 \\
8.55 \\
8.54 \\
8.53 \\
8.50 \\
8.49\end{array}$ & $\begin{array}{l}61.0 \\
61.0 \\
60.0 \\
60.0 \\
60.0 \\
60.0 \\
60.0 \\
60.0 \\
61.0 \\
61.5\end{array}$ & $\begin{array}{l}680 \\
530 \\
405 \\
375 \\
-\overline{330} \\
- \\
275 \\
218 \\
100\end{array}$ \\
\hline
\end{tabular}


microcracks caused when the alloys undergo a cubic to hexagonal transformation.

(3) The linear coefficient of thermal expansion and the temperature coefficient of Young's modulus yield a pronounced minimum value of $14.04 \times 10^{-6}$ and a very high maximum value of $2.52 \times 10^{-5}$, respectively, for the composition of $23.85 \% \mathrm{Mn}$ which falls within the $\alpha_{\text {ferromag. }}$ range. The causes of such Invar and Elinvar properties can be explained by Masumoto's rule in regard to Invar.

\section{Acknowledgment}

The authors wish to express their deep appreciation to the staff of the Research Section, Tohoku Tokushuko K.K. for carrying out chemical analysis of $\mathrm{Co}-\mathrm{Mn}$ alloys. 